Results

- Initial pilot - one school, 32 children, seven patients, four carers, six school staff;

- 2017-2018 - eight schools, 126 children, ten patients, 73 family members, 22 teaching staff, three carers (assemblies 578 attendees);

- 2018-2019 (so far) - ten schools, 116 children, 13 patients, 80 family members, 23 teaching staff, four carers, (assemblies 829 attendees). Three hospices visited and now using Schools Project to inform their own model.

Conclusion The evaluation of the schools project shows a positive impact on children, patients and wider community. We have learnt from those involved that it has reduced taboos around death and dying and has a positive effect on patients. In-depth study being explored.

\section{P-37 NORMALISING DEATH AND DYING: AN INTRODUCTION TO HOSPICE CARE FOR CHILDREN}

Claire Lane, Rachel Morris, Lorna Richardson. Marie Curie Hospice, Liverpool, UK

\subsection{6/bmjspcare-2019-HUKNC.61}

Background Death and dying are still taboo subjects within British society, and this is particularly true when discussing end-of-life with children (Christ \& Christ, 2006; Fearnley \& Boland, 2019; McManus \& Paul, 2019; Paul, 2016). There is little opportunity for children to gain understanding of palliative care, especially those whose families have not experienced terminal illness (Lawrance \& Mitchell, 2018; Paul, Cree \& Murray, 2016). A project was designed to link a Liverpoolbased hospice and a local secondary school by inviting pupils to spend time with staff and patients in the Day Therapy Unit.

Aims To raise students' awareness of palliative care and the role of the hospice within the community.

Methods Contact was made between the hospice and a local secondary school to arrange a pilot project. The school identified six students to participate based on the students' resilience and maturity. These students attended a session with hospice staff to gain some understanding of palliative care and ask questions within a supportive environment.

The students were invited to the Day Therapy Unit weekly to engage with hospice staff and patients in a range of activities. After six weeks the students were invited to run an activity for the patients.

Results Feedback received was overwhelmingly positive. The students enjoyed spending time in the hospice, with one significantly interested in volunteering on a regular basis. The patients and staff were always happy to see the students, engaging them in conversation and encouraging their participation.

Conclusions In the future we plan to engage more students in projects and aim to encourage these students to present their experiences to their peers. We will also look to measure learning objectives both before and after the students' visits.

The pilot project has shown that it is possible for children to experience our hospice in a safe and enjoyable manner, therefore gaining greater understanding around palliative care and the role of a hospice.

\section{P-38 BUZZING ABOUT COMPASSIONATE COMMUNITIES}

Debra Lawson, Helen Birch, Rachel Kennedy, Kate Tipton-Thomas. Queenscourt Hospice, Southport, UK

\subsection{6/bmjspcare-2019-HUKNC.62}

Background Queenie's Roadshow is an engagement project targeted at local schools and nurseries. Pupils receive a free presentation from the hospice's Community Fundraiser and our mascot, Queenie. The presentation gives pupils the opportunity to learn about the invaluable work that is carried out by the hospice and their wider services.

In July, schools will hold a fundraising activity or event during their Sports Day. This is the first year in which the Roadshow has run, and whilst the focus is on engaging with local schools and nurseries to increase awareness of hospice work, dying and bereavement, it is estimated that there will be an income of approximately $£ 1,000$.

Aim The aim is engagement with local schools and nurseries to develop long-lasting relationships. This will help build Compassionate Communities and increase fundraising activities.

Methods Social media marketing. This reached 1,274 people, 75 of which engaged with the Facebook post. Traditional marketing via written request (to those who had consented) to schools and nurseries did not result in any engagement.

Results Results are anecdotal at this point as the campaign is ongoing. Children have been curious and excited to engage and have conversations. This is beginning to increase awareness. To this point, six schools/nurseries are signed up to the campaign.

Conclusion We believe that by utilising our mascot effectively we will not only develop long-lasting relationships with our local schools, but we will also raise awareness and knowledge of our hospice in a way that enables conversations about dying and bereavement with young people. We can use these experiences as building blocks within the development of Compassionate Communities as well as benefitting from fundraising activity by each school/nursery.

\section{P-39 THE EVOLUTION OF AN IDEA: ESTABLISHING THE LOROS YOUTH AMBASSADOR PROGRAMME}

Abigail Wattam. LOROS, Leicester, UK

\subsection{6/bmjspcare-2019-HUKNC.63}

Background Providing opportunities to young people allows them to develop skills and experience for work, education and adulthood (NHS England, 2019; Kirkman, Sanders, Emanuel, \& Larkin, 2016). Aligned with our community development work, LOROS continues to develop its links with younger volunteers and has supported the appointment of a dedicated Youth Engagement Officer (LOROS Hospice three year strategic plan, 2019.) The LOROS Youth Ambassador Programme is striving to connect the hospice to the youth communities of Leicester, Leicestershire and Rutland.

Aims The programme aims to consolidate, expand and celebrate young people's visibility in raising awareness of a charitable organisation and developing leadership, resilience, confidence and enthusiasm (Naidoo, 2001; Great British Entrepreneur Awards, 2018).

Methods June to August 2018 - research models of existing Youth Ambassador programmes, with examples found at 
international, national and local levels. August 2018 - creation of role description and training to include mandatory and bespoke training. September to November 2018 - research and applications for funding opportunities. December 2018 to March 2019 - setting up the programme and recruitment of Youth Ambassadors.

Results

- End of November 2018: $£ 2,500$ funding offered by NHS England Takeover Challenge, with a scope to start the project in January 2019;

- March 2019: Recruitment of three Youth Ambassadors - one from Leicestershire and two from Leicester City schools and colleges;

- April 2019: LOROS Youth Ambassadors attended the first Youth Voice Summit in London, raising awareness of youth involvement in care services;

- May 2019: $£ 2,000$ funding received from Pukka Pies to support second wave of recruitment in September/October 2019;

- July to August 2019: Youth Ambassadors will be supporting the facilitation of the LOROS Hospice School and National Citizen Service Social Action Projects.

Conclusion Providing opportunities to develop leadership and other key skills of young people in the local community, LOROS will be supplying a peer-to-peer support programme; not only will the team be supporting each other, they will be providing a long-term connection to the youth communities.

\section{\begin{tabular}{|l|l}
\hline P-40 GUIDE TO OPENING UP HOSPICE CARE \\
\hline
\end{tabular}}

Helen Birch, Debbie Lawson, Rachel Kennedy. Queenscourt Hospice, Southport, UK

\subsection{6/bmjspcare-2019-HUKNC.64}

Background Queenscourt recognises the importance of raising awareness of hospice care and Compassionate Communities amongst the local population and dispel the myth that hospices are gloomy places where people go to die.

Aims We believe passionately about normalising conversation about death and dying and have engaged with a local Girlguiding (North West England) unit to work collaboratively on producing a Queenscourt Challenge Badge.

Methods Queenscourt community fundraiser initially liaised with the Guide Leader to ascertain which age groups would be involved and if any subjects were 'off limits'. It was agreed that ALL sections should be involved from Rainbows, aged five to Rangers aged eighteen; no age group was excluded. The Queenscourt Challenge badge will incorporate all five essential elements (Girlguiding).

The community fundraiser and clinical staff considered some key elements of hospice care: themes included are: therapies, nutrition, volunteering, medicine and treatments, pets as therapy, clergy, importance of the environment and gardens and Transport and fundraising, to name a few.

Results An afternoon has been arranged when the Guides will visit the hospice, there will be numerous 'stations' set up around the hospice demonstrating the above, the Guides will have to engage with staff and undertake certain hospice related challenges appropriate to their age and topic.

Conclusion Working collaboratively with a local Girlguiding group has opened up the perception of hospice care to a whole new group of young people. We hope to continue this work with more Girlguiding units across our locality promoting our work around Compassionate Communities, one of our key strategic objectives. The work has also improved professional relationships between clinical and corporate teams within the hospice, each becoming more aware of each other's professional roles and responsibilities.

\section{P-41 'DYING NATTERS'- CREATING DEATH-POSITIVE COMMUNITY CONVERSATIONS}

Gemma Allen, Lucy Martin. Mary Stevens Hospice, Stourbridge, UK

\subsection{6/bmjspcare-2019-HUKNC.65}

Background Dying Matters Dudley is a coalition of organisations, encouraging communities in courageous conversation and creating opportunities for people to speak freely and honestly about death and dying.

Aims To enable people to have conversations and support one another, preparing and planning for end of life. To provide an initial platform during awareness week, with a varied itinerary of events, incorporating practical support, literacy, arts and theatre, whilst reaching out to marginalised communities. Methods Steering group of partners including funeral directors, hospice, NHS trust, public health, soul midwives, libraries and other organisations. NHS funding allowed free events listed below, a bespoke website and social media platforms. Activities at events included advance care planning, arts and crafts and a 'before I die' board.

- Four death cafés hosted in libraries, one specifically for young people;

- Poetry workshop;

- 'The Diary Rooms' camper van, touring the region filming video diaries aimed at people living in deprived areas, BAME \& LGBT communities, learning disability centres, homeless people's hostel and higher education college;

- Craft and information event hosted at funeral directors aimed at children under five;

- A theatre performance and lecture;

- Hospital based drop-in hub.

Results All events were well attended by members of the public. Video diaries were collected to share across the borough. A social media profile created curiosity and was successful in encouraging people to attend events.

Conclusion The majority of people engaged with events and positively embraced conversations about death and dying. Following this success we have planned:

- Attending an under $5 \mathrm{~s}$ crafts day supporting activities and providing child bereavement support resources to adults;

- Homeless people's hostel open day;

- Planning for other regular events and Dying Matters Week 2020.

\section{P-42 THE DIARY ROOMS: CREATIVE CONVERSATIONS}

Gemma Allen. Mary Stevens Hospice, Stourbridge, UK

\subsection{6/bmjspcare-2019-HUKNC.66}

Aim To reach out to more people during Dying Matters Week, enabling those who may be marginalised at end of life the opportunity to record their thoughts, wishes and experiences on film around death, dying and bereavement. 